APRESENTAÇÃO

Nos anos 1980, saindo do regime militar e ensaiando ainda um modelo de democracia, o país passava por mudanças profundas. E não apenas no campo político e econômico. Novos, e nem tão novos assim, modelos de comportamento, de pensamento, subiam à cena, numa efervescência cultural que marcou a década e, claro, também deixou suas marcas na universidade.

Na UERJ, vivemos nesse período uma série de transformações estruturais, em todos os níveis, incluindo o da pós-graduação, ainda no seu rascunho.

Dirce Côrtes Riedel, educadora, crítica literária, teve papel determinante nessas mudanças. Sua batalha contínua pela valorização da literatura, dentro e fora da universidade, tornou possível a criação do primeiro curso lato sensu do Programa de Pós-Graduação em Letras da UERJ, o de Especialização em Literatura Brasileira, logo no início da década (1982).

Também graças, sobretudo, ao seu esforço e dedicação, finalmente tivemos a primeira pós-graduação stricto sensu da Letras, em 1988, com o Mestrado em Literatura Brasileira.

Haveria vários motivos para homenagearmos Dirce Riedel com um número especial da Matraga. O mais relevante, no entanto, talvez seja muito simples: foi ela quem criou a Matraga.

Com o nome tomado de empréstimo ao personagem de Guimarães Rosa - de quem foi grande estudiosa e amiga pessoal -, Matraga surgia com uma proposta inovadora. $\mathrm{E}$ isso fica evidente já no primeiro número, que veio a público no meio da década: 1986 .

Dirce cuidou de cada detalhe do número 0 da revista - ver fac simile nas páginas seguintes -, desde a escolha do papel (mais leve do que o tradicional), até todo o acompanhamento do projeto de diagramação, passando, claro, pelo projeto editorial como um todo.

O projeto gráfico - encomendado à artista plástica Maria Moreira trazia na capa apenas o essencial, sendo a maior parte do espaço ocupado por linhas em branco. A ideia de produzir uma revista arejada, sem o peso da maioria das revistas acadêmicas da época, começava a se anunciar já pela capa, que de algum modo referendava a hipótese de que todo texto, acadêmico ou não, só se completa quando o leitor o escreve. 

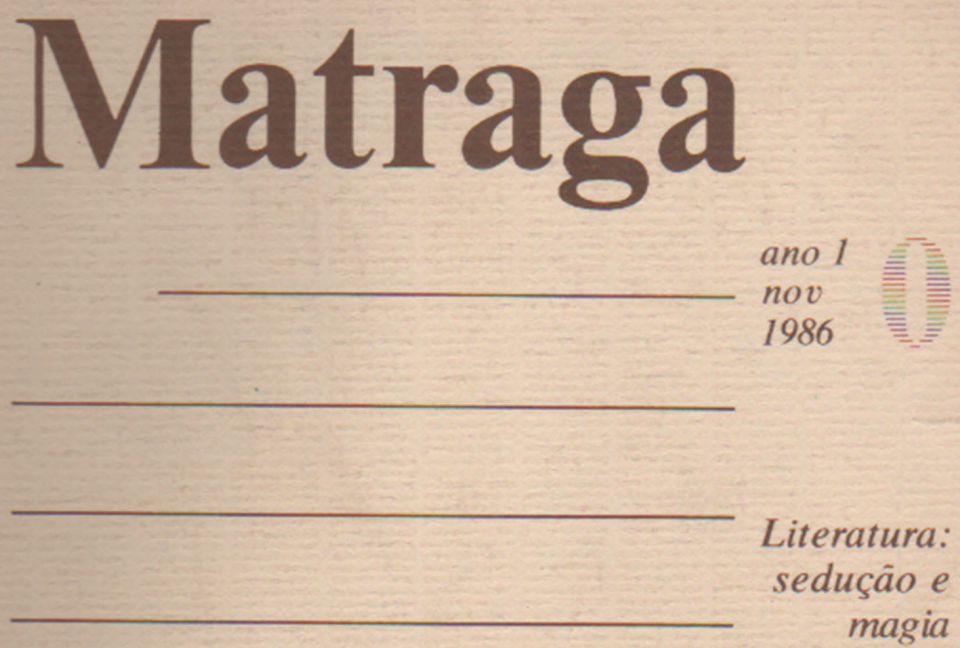

\section{Filosofia e poesia}


Na página de rosto, antes mesmo de qualquer ficha técnica, a citação de Barthes anunciava a proposta interdisciplinar da revista. Num canto, como se fosse uma anotação manuscrita, lia-se que Matraga chegava para estimular o prazer da leitura e suprimir as fronteiras entre as diversas áreas do conhecimento na universidade.

No miolo, a diagramação, com largas margens e uma espécie de anotações de leitura - brevíssimos comentários, anônimos, colocados aqui e ali, ao lado do texto - sugeria ao leitor da revista que fizesse o mesmo naquelas páginas, marcando Matraga com sua própria caligrafia e tomando-a, de vez, para si.

O sumário apontava para o modo como a revista foi pensada, por Dirce Riedel e por seus colaboradores, em especial Renato Cordeiro Gomes, Vera Follain Figueiredo, Carlos Lima, Marília Rothier Cardoso e Italo Moriconi. Depois de um ensaio inicial, de fundo, vinha a seção PISTAS, com resenhas e também dois ensaios de caráter multidisciplinar. A seção ELOS cabia a um convidado, de outra área. Na Matraga 0, coube a Gerd Bornheim a tarefa. Por fim, em OUTRAS PALAVRAS, abria-se espaço para poemas e contos inéditos.

Esse modelo seria inviável hoje, sabemos, mas traduz um desejo de renovação, de abrir as portas da academia de Letras, não só as externas pela proposta interdisciplinar -, mas também as portas de dentro da casa, que deixavam passar prazerosamente, por entre os ensaios acadêmicos, poemas e contos.

Signo da ousadia que sempre guiou Dirce Côrtes Riedel está também na primeira resenha de PISTAS. Quando muitos negavam (e ainda negam) a validade de um estudo do presente, do autor ainda vivo, ainda produzindo, Dirce defendia aqueles que se lançavam ao desafio de encarar o texto recém-saído da livraria. E foi o que fez ao escrever ela mesma, para o primeiro número da Matraga, uma resenha de $A$ hora da estrela, de Clarice Lispector, publicado naquele ano de 1986, poucos meses antes da estreia da revista.

$* * *$

Este número especial da Matraga, dedicado a Dirce Côrtes Riedel, traz três ensaios escritos especialmente para a ocasião - por Ivo Barbieri, Eneida Maria de Souza e Maria Helena Werneck - que abordam diferentes aspectos da sua obra. Há também três depoimentos inéditos, de Luiz Costa Lima, Silviano Santiago e Vera Casa Nova. 


\section{Matraga}

Se todas as nossas disciplinas deves-

sem ser expulsas do ensino, exceto uma, a

disciplina literária é que deveria ser salva, pois

todas as ciências estão presentes no momento

literário. Entretanto, e nisso verdadeiramente

enciclopédica, a literatura faz girar os saberes,

não fixa, não fetichiza nenhum deles; ela thes

dá um lugar indireto e esse indireto é precioso

Roland Barthes

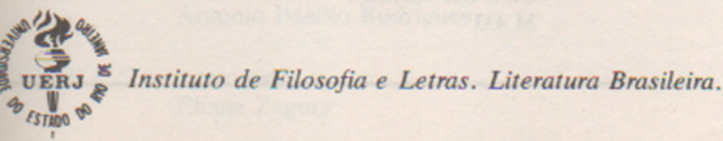

Matraga quer estimular o prazer da leitura e suprimir as fronteiras entre as diversas áreas de conhecimento na universidade. 


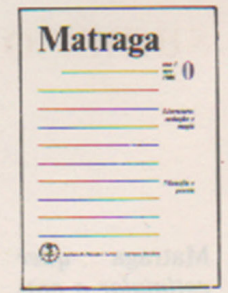

n? $0 \cdot$ ano I - nov $\cdot 1986$

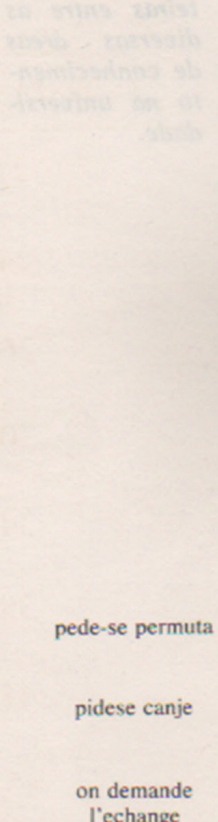

si chiede lo scambio

man bittet um austausch

we ask for exchange

\section{DIRETORIA}

Dirce Côrtes Riedel

\section{ASSESSORIA}

Ítalo Moriconi Jr.

Renato Cordeiro Gomes

Vera Follain de Figueiredo

Carlos Lima

\section{CONSELHO EDITORIAL}

Fátima Cristina Dias Rocha

Ivo Barbieri

Maria Consuelo Cunha Campos

Marilia Rothier Cardoso

Roberto Acizelo de Souza

Terezinha Peres de Castro

\section{ENDEREÇO DA REDAÇĀO}

Rua São Francisco Xavier. 524

Pavilhão Joâo Lyra Filho S-1006,

Bloco A

20550 Rio de Janeiro, RJ

Tels.: 264-8143 ou 284-8322

Ram. 2417 e 2507
CONSELHO CONSULTIVO

Antonio C. de Mello e Souza Boris Schneiderman

Celso Pereira de Sá

Eliane Zagury

Eneida Maria de Souza

Homero Salazar

Jader Beluzzi Martins

Jader Brito

Leticia Mallard

Luiz Costa Lima

Marilena Ramos Barbosa

Orlando da Fonseca Pires

Sebastião Uchoa Leite

\section{PROJETO GRÁFICO}

Maria Moreira

\section{ARTE FINAL}

Eleonora Ballista

\section{PRODUÇĀO EXECUTIVA}

Centro de Produção da UERJ

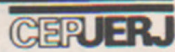

Matraga. - vol. 1. n? 0 (nov. 1986)

- Rio de Janeiro : UERJ: IFL 1986 - .

$$
\text { V. : } 23 \mathrm{~cm} \text {. }
$$

Quadrimestral.

1. Literatura brasileira - Periódicos. Universidade do Estado do Rio de Janeiro. Instituto de Filosofia e Letras.

CDDB 869.05

CDU $869.0(81)(05)$

M 433 


\section{matraga}

MATRAGA não é Matraga, não é nada -

Matraga é Esteves. Augusto Esteves, filho do Coro-

nel Afonsão Esteves, das Pindaíbas e do Saco-do-

Embira.

- Eu vou p'ra o céu, e vou mesmo, por

bem ou por mal!... E a minha vez há de chegar... P'ra

o céu eu vou, nem que seja a porrete!...

GUIMARÃES ROSA 


\section{sumário}

A HORA DA ESTRELA: compromisso com a palavra

Dirce Côrtes Riedel

Uma temporada no pais do tédio: BLECAUTE

Marco Antonio Gutierrez

COM LICENÇA EU VOU À LUTA: a maioridade pela escrita.

Maria Helena Werneck

MANUEL BAND :IRA. a poesia

Néls in Rodrigues Filho

A tradução cênica de O ALIENISTA. de Machado de Assis.

Renato Cordeiro Gomes

3x4: poesia à beira do abismo

Italo Moriconi Jr.

O TRIBOFE: apostando na revista: logro e lucro

Marilia Rothier Cardoso

O escândalo de DONA GUIDINHA DO POÇO.

Roberto Acizelo de Souza

LUCAS PROCÓPIO: pessoa persona

Maria Consuelo Cunha Campos

OS NÓS F OS LAÇOS que se atam e se desatam

Antonio Basílio Rodrigues

BORGES sem retoque

Eliane Zagury 


\section{sumário}

55

IDENTIDADE CULTURAL LATINO-AMERICANA

J. Silveira da Costa

57

UNIVERSIDADE: UM ORGANISMO DOENTE

Ivo Barbieri

ELOS

61

FILOSOFIA E POESIA

Gerd Bornheim

OUTRAS PALAVRAS

73

POEMAS

Geraldo Ramos Ponte Jr.

Renato Casimiro

Roberto Corrêa dos Santos

Wilberth Clayton

80

CONTOS

Thales Pontes Luz

Flávio Martins Carneiro

COLABORADOR CONVIDADO: Professor-Adjunto do Instituto de Filosofia e Ciências Sociais da Universidade Federal do Rio de Janeiro - UFRJ Autor de O SENTIDO E A MÁSCARA e O TEATRO E A CENA DIVIDIDA. além de outros livros de filosofia. 
Os demais artigos versam sobre temas trabalhados pela homenageada ao longo da sua carreira: Machado de Assis e Guimarães Rosa, autores visitados por Dirce Riedel com o interesse crítico que merecem. Há também considerações sobre seu papel como autora de livros didáticos sobre literatura - modo seguro de trabalhar pela divulgação do texto literário de forma prazerosa, via aprendizado. Ainda neste número, acolhemos, como usual, resenhas críticas de obras do campo literário.

Desejamos a todos uma boa leitura.

Flávio Martins Carneiro Andréa Sirihal Werkema 